\title{
Exploration on Prediction and Early Warning Technology for Investment Completion of 10 kV And Below Power Grid Infrastructure Projects
}

\author{
Lei $\mathrm{Ma}^{1 *}$, Fan Wen², Jian Huang ${ }^{3}$, Xia Pan ${ }^{3}$, Feifei Xu ${ }^{3}$, Wenjun $\mathrm{Xu}^{3}$, Jinping $\mathrm{Shi}^{3}$ \\ ${ }^{1}$ State Grid Zhejiang Electric Power Co., Ltd., Hangzhou, Zhejiang, 310007, china \\ ${ }^{2}$ State Grid Zhejiang Economic Research Institute, Hangzhou, Zhejiang, 310008, china \\ ${ }^{3}$ State Grid Zhejiang Electric Power Co., Ltd. Lishui Power Supply Company, Lishui, Zhejiang, 323000, china
}

\begin{abstract}
The external severe and complex economic situation has a great impact on the efficiency of the company's investment implementation. The in-depth implementation of the lean investment management concept also puts forward new requirements for improving the extensive distribution network investment management mode. In addition, in recent years, the proportion of investment in distribution network projects of $10 \mathrm{kV}$ and below has increased, and its management mode is difficult to keep up with the new investment management requirements. Therefore, this project takes the infrastructure projects of $10 \mathrm{kV}$ and below as the research object, constructs the investment plan curve by studying the business rules of construction, accounting and materials, and deepens its application in the early warning of investment plan implementation based on the investment plan line, and provides an effective support tool for the investment lean management and control of distribution network.
\end{abstract}

\section{Research background and objectives}

The domestic and international economy is facing downward pressure. Meanwhile, the government's request to "reduce the electricity price" makes the operation of power grid companies under pressure, which puts forward requirements for improving the efficiency of power grid investment by relying on endogenous power; the in-depth implementation of the company's internal lean investment concept is also constantly strengthening to find a more scientific and reasonable new mode of power grid investment management[1-2]. In addition, in recent years, the national policy and the requirements of power grid development make the investment of power grid incline to the distribution network continuously, and the investment proportion is also rising. However, its extensive management mode is difficult to adapt to the realization of the company's distribution network investment efficiency target under the background of transmission and distribution price reform. Therefore, it is urgent to explore the lean quantitative management mode of investment implementation process of distribution network project[3-5].

\section{Research objectives}

This project takes the power grid infrastructure projects of $10 \mathrm{kV}$ and below as the research object, and builds the investment execution plan curve (investment plan line) on the basis of the research on the occurrence law of key process data such as investment execution, construction, accounting and materials of power grid infrastructure projects. Based on the curve, it can deepen its application in the early warning of investment plan implementation and construct the dynamic forecast of investment execution deviation The alarm model provides an effective quantitative support tool for the realization of dynamic early warning of investment management process of distribution network projects and the positioning and analysis of investment execution problems.

\section{Business Law Analysis of investment execution process of distribution network project}

Research the relevant management data of key business departments involved in distribution network project management, design relevant scenarios, collect relevant business data, and carry out rule mining. The details are as follows:

*Corresponding author’s e-mail: malei@zj.sgcc.com.cn 


\subsection{Data mining of key characteristics of construction chain}

Collect the planned and actual start-up and completion time data of key nodes of multi-dimensional attribute project (Different types, regions, construction nature, construction purpose, etc), and use statistical analysis technology to analyze the overall construction period and key node time interval of distribution network project, so as to provide prediction basis for the preparation of investment planning line. The results are as follows:

Characteristics of construction period: from the construction period of sample projects, it can be seen that the construction period of more than $59 \%$ of the sample projects is short, with an average construction period of 2.2 months; for $35 \%$ of the distribution network projects, the average construction period is 8 months; for $6 \%$ of the distribution network projects, the average construction period is 15.1 months. According to the analysis of data statistics, the construction period of distribution network project is basically within 5 months.

Table 1. Statistics of construction period of distribution network infrastructure projects

\begin{tabular}{|c|c|c|}
\hline $\begin{array}{c}\text { Interval of construction } \\
\text { period }\end{array}$ & $\begin{array}{c}\text { Interval of } \\
\text { construction } \\
\text { period (months) }\end{array}$ & $\begin{array}{c}\text { Proportion of } \\
\text { quantity }\end{array}$ \\
\hline $\begin{array}{c}\text { Construction period }<=5 \\
\text { months }\end{array}$ & 2.2 & $59 \%$ \\
\hline $\begin{array}{c}5 \text { months }<\text { Construction } \\
\text { period }<=12 \text { months }\end{array}$ & 8 & $35 \%$ \\
\hline $\begin{array}{c}\text { Construction period }>12 \\
\text { months }\end{array}$ & 15.1 & $6 \%$ \\
\hline Total & 4.9 & $100 \%$ \\
\hline
\end{tabular}

By analyzing the time interval between the overall key milestones of the project, it is found that the time interval from project approval to preliminary design approval is about 41 days, the interval from preliminary design approval to project commencement is about 58 days, the interval from project commencement to project completion is about 148 days, the interval from project completion to completion acceptance is about 6 days, and the interval from completion acceptance to completion settlement is about 61 days The time interval between the project closure and ERP system is about 170 days.

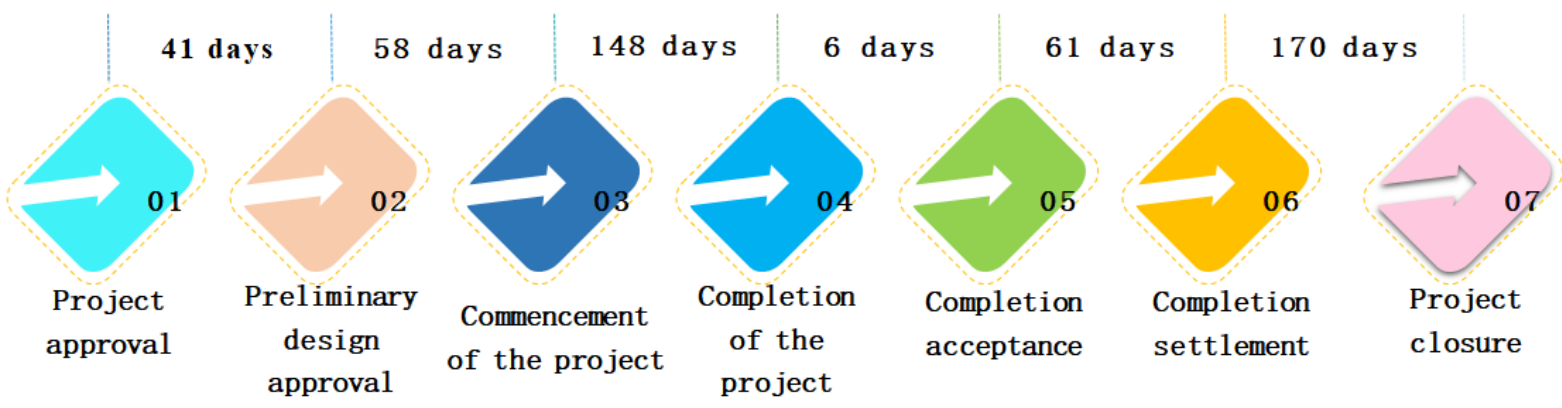

Figure 1. Time interval of key milestone nodes of the project

\subsection{Data mining of key characteristics of material chain}

Collect the relevant sample data, carry out the interval rule mining between the material receiving time and the key milestone node time, and study the rule of the proportion of the key material collection value in the key milestone nodes such as the commencement. The specific results are shown in the table below:
(1) The average entry frequency of main materials used in the project construction is 1 to 2 times;

(2) The main distribution network materials collection time is about 2 to 3 months before the actual construction (Such as: AC transformer, switch cabinet, cable, etc).

(3) The proportion of key materials in the project budget estimate is: AC transformer accounts for about $17 \%$ (about $34 \%$ of equipment purchase cost estimate), and switch cabinet (box) accounts for about $10 \%$.

Table 2. Frequency and time of main materials receiving

\begin{tabular}{|c|c|c|c|}
\hline Type of material & $\begin{array}{c}\text { Average entry and settlement } \\
\text { frequency of main material type } \\
\text { project materials (times) }\end{array}$ & $\begin{array}{c}\text { Deviation between earliest } \\
\text { material receiving time and } \\
\text { starting time (months) }\end{array}$ & $\begin{array}{c}\text { Ratio of main material } \\
\text { requisition to project budget } \\
\text { estimate before construction }\end{array}$ \\
\hline Conductor and ground wire & 2 & -2.28 & $6 \%$ \\
\hline Cable & 2 & -3.16 & $8 \%$ \\
\hline Tower & 2 & -1.78 & $10 \%$ \\
\hline Iron accessories & 1 & -0.59 & $7 \%$ \\
\hline Cable accessories & 1 & -3.12 & $7 \%$ \\
\hline High voltage fuse & 1 & -2.93 & $10 \%$ \\
\hline Switch cabinet (box) & 2 & -3.34 & \\
\hline
\end{tabular}




\begin{tabular}{|c|c|c|c|} 
Low voltage panel (cabinet), box & 1 & -1.18 & $9 \%$ \\
\hline AC transformer & 1 & -2.89 & $17 \%$ \\
\hline Lightning arrester & 1 & -2.16 & $14 \%$ \\
\hline
\end{tabular}

\subsection{Analysis on the characteristics of cost entry}

According to the collected cost entry data, the time sequence of key milestone nodes is studied. The main contents include:

(1) Analysis on the proportion of project materials and services with multi-dimensional attributes

Through collecting the completion final accounts data of typical sample projects put into operation in 2019, the proportion of materials and service costs is $46 \%$ and $54 \%$ respectively; from the perspective of further distinguishing the four costs, the construction cost, installation cost, equipment purchase cost and other costs account for $6 \%, 39 \%, 46 \%$ and $10 \%$ respectively.

(2) Mining of material and service cost entry rules before project commencement

According to the cost Sub Ledger data of sample projects and the actual starting time, the proportion of material and service cost entry before project commencement is analyzed.

(1) The average proportion of service cost recorded accounts for about $8 \%$ of the project budget estimate. According to the types of sample projects, except for the low entry rate of $4 \%$ for cable lines, other types of projects such as overhead lines, mixing of distribution transformers and cables, and overhead cables are basically accounted for about $8 \%$.

(2) The average proportion of material cost recorded accounts for about $24 \%$ of the project budget estimate. According to the types of sample projects, the proportion of materials received before the construction of projects mainly composed of cables and AC transformers was relatively high, ranging from $30 \%$ to $40 \%$. The average proportion of materials received before the construction of projects mainly composed of overhead lines was $13 \%$. According to the results of project type analysis, it is found that for projects requiring more customized materials (such as AC transformers, cables, etc.), the proportion of materials arriving in advance is relatively large before the commencement of construction; for projects requiring more general materials (such as overhead lines), the proportion of materials received in advance is significantly lower before the commencement of projects.

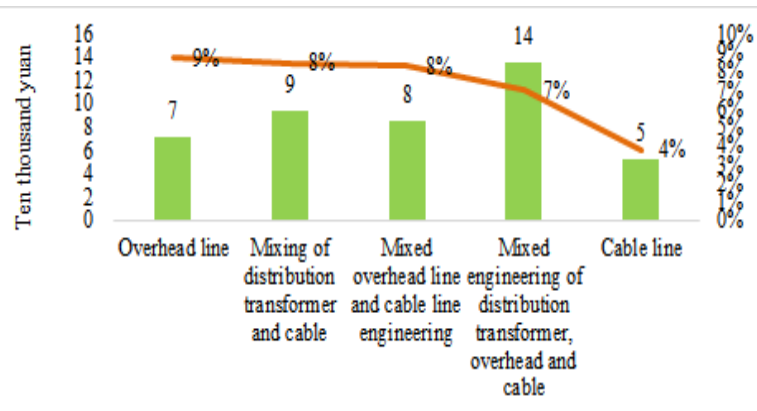

Average value of service charge recorded before construction

- Proportion of service charge recorded in budget estimate before construction

Figure 2-a. Chart of service cost entry before construction

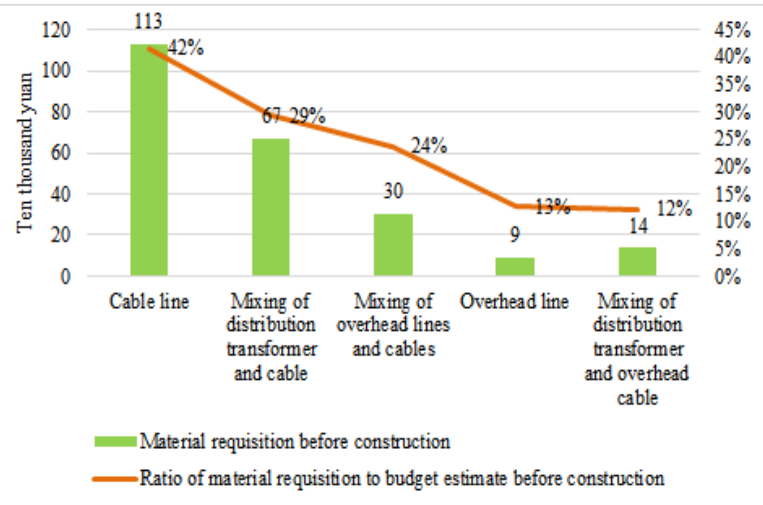

Figure 2-b. Chart of material cost entry before construction

(3) Research on the time sequence of service charge entry

The service cost data of 105 sample projects are collected, and the ratio of each month's service cost to the project budget is converted based on the starting point of the project. This paper uses cluster analysis method to cluster the service charge monthly entry time series curve, and summarizes the business characteristics of various service cost entry curve, so as to provide reference for the prediction of subsequent service cost entry sequence.

(1) Determination of the best classification number

Using $\mathrm{R}$ language clustering analysis algorithm to determine the best classification number of service cost entry curve of sample project. According to the principle of cluster analysis, when the number of clusters (k) is less than the optimal number of clusters, the increase of $\mathrm{k}$ will greatly increase the degree of aggregation of each cluster, so the decrease range of sum of squares of error (SSE) will be greater. When $\mathrm{k}$ reaches the optimal number of clusters, the aggregation degree obtained by increasing $\mathrm{k}$ will decrease rapidly, so the decrease range of SSE will drop sharply, and then tend to be stable with the increase of $\mathrm{k}$. The first point that tends to be stable is the appropriate $\mathrm{k}$ value.

It can be seen from the figure below that when $\mathrm{k}$ is from 1 to 3 , the decreasing range of SSE is $a$ and $b$ respectively, and the decreasing range is larger. When $\mathrm{k}$ 
is from 3 to 4 , the decrease range of SSE is c, which is smaller than that of segment $\mathrm{b}$. It shows that when $\mathrm{k}$ is taken as 4 , there is an inflection point, that is, the first point tends to be stable. Therefore, the best clustering should be divided into four groups.

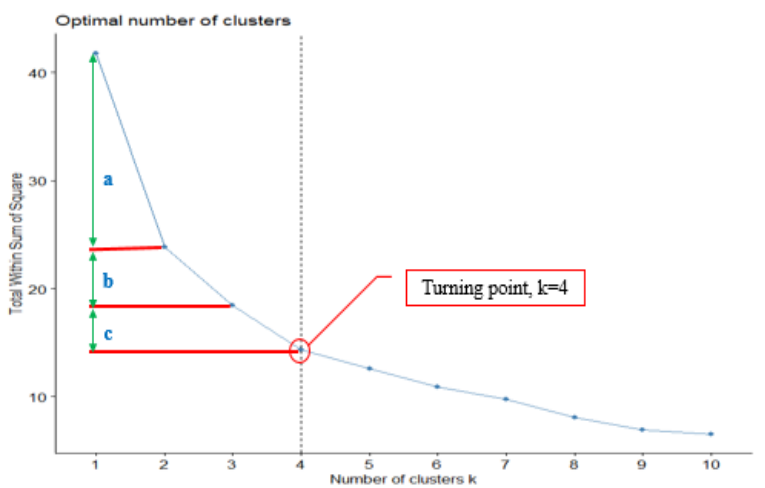

Figure 3. K-value trend chart

(2) Analysis of clustering results
According to the above grouping results, the typical curves of each group were drawn respectively, as shown in the following figure:

Note: 1. Samples with inconsistent recording periods shall be supplemented according to the accumulated value of the last month; 2 . The denominator of service charge entry sequence is project budget.

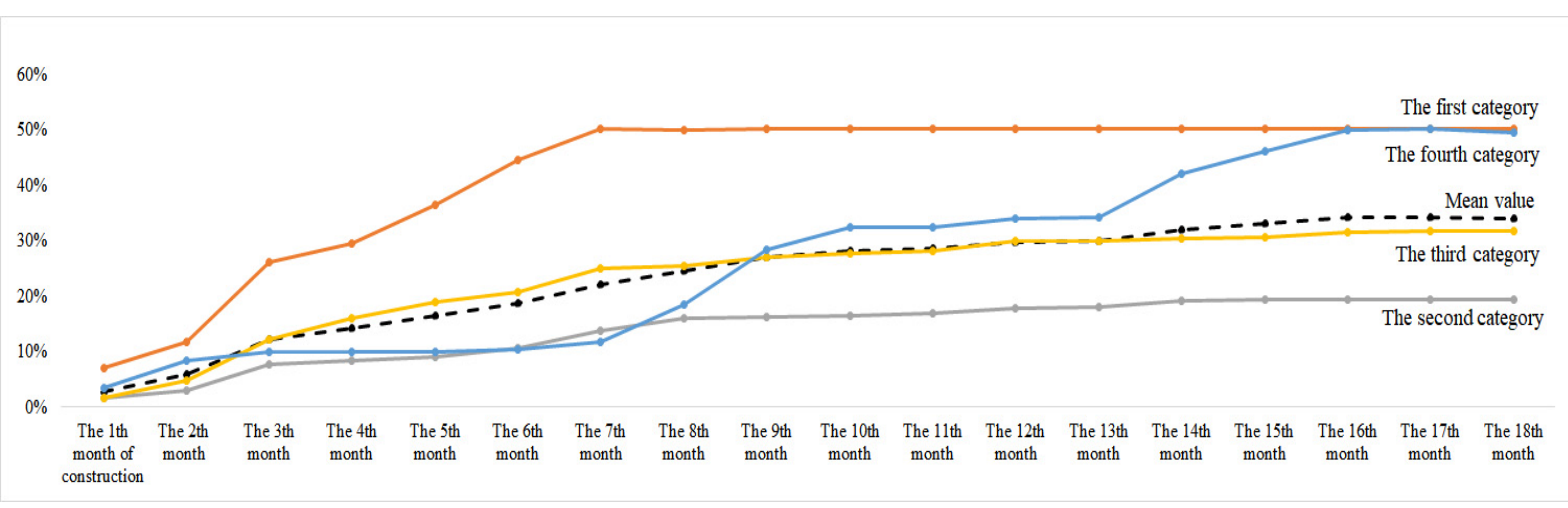

Figure 4. Clustering results of service cost entry curve of sample projects

Observe the above figure and analyze the characteristics of four types of cost entry, which are as follows:

Overall characteristics: the service cost of the first and fourth categories (There were 41 samples in total) accounts for about $50 \%$ of the project budget estimate, of which 36 are reconstruction projects; the service cost of the third sample (43 samples) accounts for about $30 \%$ of the project budget, including 30 new projects; the service cost of the second sample accounts for about $20 \%$ of the project budget.

The first category: 16 samples. Through the analysis of such projects, it is found that the recording period of service fees of such projects is relatively concentrated, and the time is basically consistent with the construction period; the sample projects are all reconstruction of overhead line projects or types of overhead lines, therefore, the characteristic coordinates of such sample projects are: (reconstruction, mixing of overhead lines and cable lines).

The second category: 37 samples. Analysis of this kind of project shows that the service charge of this kind of project has a long accounting period, and the overall service fee accounts for a relatively low proportion. By observing 37 samples, it is found that 32 sample projects contain cable line engineering, and the number of new construction and reconstruction projects accounts for $50 \%$ respectively. Therefore, the characteristic coordinates of such sample projects are: (new construction and reconstruction, cable line engineering).

The third category: 43 samples. Analysis of such projects shows that the recording period of service fee is long, which is basically close to the sample average curve, and the service cost accounting for about $30 \%$ of the project budget estimate. By observing 43 samples, 38 projects of overhead type were found, of which 25 were newly built. Therefore, the characteristic coordinates of this kind of sample project are: (new construction, overhead line engineering).

The fourth category: 25 samples. Analysis of this kind of project shows that the service charge of this kind of project has a long recording period, and it presents a ladder like entry feature. The sharp increase of the curve is mainly caused by the progress payment and the final payment of the project. The characteristic coordinates of such sample projects are: (reconstruction, overhead line engineering). 


\subsection{Analysis on balance rate of distribution network project}

Collect budget estimate data and final account data of sample projects. According to the formula: balance rate $=$ (final account data - budgetary estimate data) / budget data, the average balance rate level of sample distribution network project is $10 \%$. According to the four costs, the balance rate of construction engineering cost is $22 \%$, that of installation engineering cost is $9 \%$, that of equipment purchase cost is $22 \%$, and that of other expenses is $40 \%$.

\section{Construction of investment prediction model for power grid infrastructure with $10 \mathrm{kV}$ and below}

On the basis of the above research, the construction of project investment planning line is carried out. The ideas are as follows:

(1) Determine the start-up and commissioning time of the project

According to the project type of the project, match the required construction period of the project, determine the planned investment completion interval, and provide the basis for the construction of the planned investment line in the next step.

(2) Forecast of investment plan line

In order to form the planned investment line from the start-up to the commissioning node, the investment completion time series forecast is divided into two parts: the planned material line and the planned service line.

(1) Planned material line: determine the main materials required according to the project type, and determine the investment planned material line in combination with the frequency of material requisition and the proportion of the received value.

(2) Planned service line: according to the entry rules of service fees of different project types, the service fees in the process of project construction investment are predicted. The details are as follows:

Starting time point: the amount of service fee included in the investment completion at the starting point is predicted according to the proportion of the account entered before the commencement.
Construction process: according to the attribute of the project to be measured, match the characteristics of project cost entry sequence, and predict the monthly service investment completion.

(3) Investment planning line: the planned material line and the planned service line are combined monthly to generate the planned investment completion line, which provides the basis for constructing the deviation threshold calculation model in the next step.

(3) Example

According to the above analysis ideas, a $10 \mathrm{KV}$ project is selected for verification. The specific situation of the project is as follows: the total investment of the $10 \mathrm{kV}$ project is 453800 yuan, the project type is the mixed project of overhead cable, and the construction nature is reconstruction. The predicted planned material line and service line are as follows:

(1) Forecast of planned service line: at the commencement point, the entry amount is calculated according to the entry proportion of service fee before the commencement; after the commencement, the service line prediction time sequence at the commencement time point is matched according to the construction attribute of the project, and it is classified into the first category. Therefore, the forecast service time sequence $=$ project estimate * (1-balance rate) * the monthly entry proportion (50\%) of the first type of service cost.

(2) Forecast of planned material line: assuming that the proportion of key materials receiving and completing is $24 \%$ before the commencement of construction, the materials will basically arrive at the starting time. The predicted material cost at the starting point $=$ project budget * (1-balance rate) $*$ the proportion of the value of main materials received (24\%); after the commencement, since the construction period of distribution network is basically short, it is assumed that the distribution network will be collected within three months after the commencement. Therefore, the proportion of remaining materials $25 \%$ (1-the first category of service costs accounted for $50 \%$ each month-the ratio of material requisition before construction is $24 \%$ ), will be shared within three months after the commencement.

Table 3. Prediction of curve proportion

\begin{tabular}{|c|c|c|c|c|c|c|c|c|c|c|}
\hline $\begin{array}{c}\text { Forecast proportion of } \\
\text { accumulated investment }\end{array}$ & $\begin{array}{c}\text { 1st } \\
\text { month }\end{array}$ & $\begin{array}{c}\text { 2nd } \\
\text { month }\end{array}$ & $\begin{array}{c}3 \text { rd } \\
\text { month }\end{array}$ & $\begin{array}{c}4 \text { th } \\
\text { month }\end{array}$ & $\begin{array}{c}5 \text { th } \\
\text { month }\end{array}$ & $\begin{array}{c}6 \text { th } \\
\text { month }\end{array}$ & $\begin{array}{c}7 \text { th } \\
\text { month }\end{array}$ & $\begin{array}{c}\text { 8th } \\
\text { month }\end{array}$ & $\begin{array}{c}9 \text { th } \\
\text { month }\end{array}$ & $\begin{array}{c}10 \text { th } \\
\text { month }\end{array}$ \\
\hline $\begin{array}{c}\text { Forecast ratio of } \\
\text { investment plan line }\end{array}$ & $32 \%$ & $45 \%$ & $67 \%$ & $79 \%$ & $85 \%$ & $94 \%$ & $99 \%$ & $99 \%$ & $99 \%$ & $99 \%$ \\
\hline $\begin{array}{c}\text { Among them: forecast } \\
\text { ratio of material }\end{array}$ & $24 \%$ & $33 \%$ & $41 \%$ & $49 \%$ & & & & & & \\
\hline Forecast ratio of services & $7 \%$ & $12 \%$ & $26 \%$ & $30 \%$ & $36 \%$ & $45 \%$ & $50 \%$ & $50 \%$ & $50 \%$ & $50 \%$ \\
\hline
\end{tabular}




\section{Application of investment planning line for $\mathbf{1 0} \mathrm{kV}$ and below power grid infrastructure}

The planned investment line constructed by the above laws can assist the dynamic early warning of investment execution deviation. The project threshold is determined by comparing the planned and actual investment completion lines and combining with the multi-dimensional attributes of the project. According to the calculation threshold, the dynamic early warning model of multi-dimensional index deviation is constructed to realize the dynamic early warning of distribution network project, and provide support for improving the management level of distribution network project.

(1) Measurement of deviation threshold

The big data technology is used to classify the investment execution deviation curve of different attribute projects and the deviation curve between investment and entry, and determine the threshold curve of actual investment execution deviation plan in the construction process, as well as the deviation threshold between actual investment and entry, so as to provide parameter standard for dynamic early warning of deviation of multi-dimensional indicators.

(2) Constructing dynamic warning model of deviation

According to the above measured deviation threshold, the parameters of deviation dynamic early warning model are set, and the deviation dynamic early warning model is constructed according to the "input measurement output" framework. By comparing the actual investment implementation with the planned investment, early warning is carried out for the projects that exceed the deviation threshold. According to the results of early warning, a list of early-warning projects is generated, and the abnormal situation in the process of project investment implementation can be located timely and accurately. To provide effective support for more efficient and accurate problem-solving projects.

\section{Conclusion}

This project takes the power grid infrastructure projects of $10 \mathrm{kV}$ and below as the research object, through the in-depth study of its construction, accounting and materials and other data business rules, constructs the investment planning line, and based on the investment planning line, deepens its application in the early warning of investment plan implementation, so as to realize the accurate positioning of abnormal situations in the process of investment implementation of distribution network projects, and provide effective support for lean management and control of investment process.

\section{Acknowledgments}

This paper is supported by Lishui Zhenghao Electric Power Industry Group Co., Ltd

\section{References:}

1 Zheng, Y.B. (2019) Construction and management of $10 \mathrm{kV}$ distribution network project New technology and new products in China.

2 Guan, E.P. (2019) The whole process management of distribution network construction in power engineering. Science and technology economy guide.

3 Cai, R. (2019) Analysis of the whole process management of power engineering distribution network construction. Mechanical and electrical safety.

4 Zheng, L. (2011) Research on investment optimization management method and application of distribution network construction project.

5 Qi, L., Zeng, M. (2012) Investment optimization management of distribution network construction project. Management of power enterprises in China 